This item was submitted to Loughborough's Research Repository by the author.

Items in Figshare are protected by copyright, with all rights reserved, unless otherwise indicated.

\title{
Young people: a phenomenographic investigation into the ways they
} experience information

\section{PLEASE CITE THE PUBLISHED VERSION}

http://dx.doi.org/10.1515/libri-2012-0012

\section{PUBLISHER}

(c) Walter de Gruyter

VERSION

VoR (Version of Record)

\section{LICENCE}

CC BY-NC-ND 4.0

\section{REPOSITORY RECORD}

Smith, Marian, and Mark Hepworth. 2019. "Young People: A Phenomenographic Investigation into the Ways They Experience Information”. figshare. https://hdl.handle.net/2134/13122. 
This item was submitted to Loughborough's Institutional Repository (https://dspace.lboro.ac.uk/) by the author and is made available under the following Creative Commons Licence conditions.

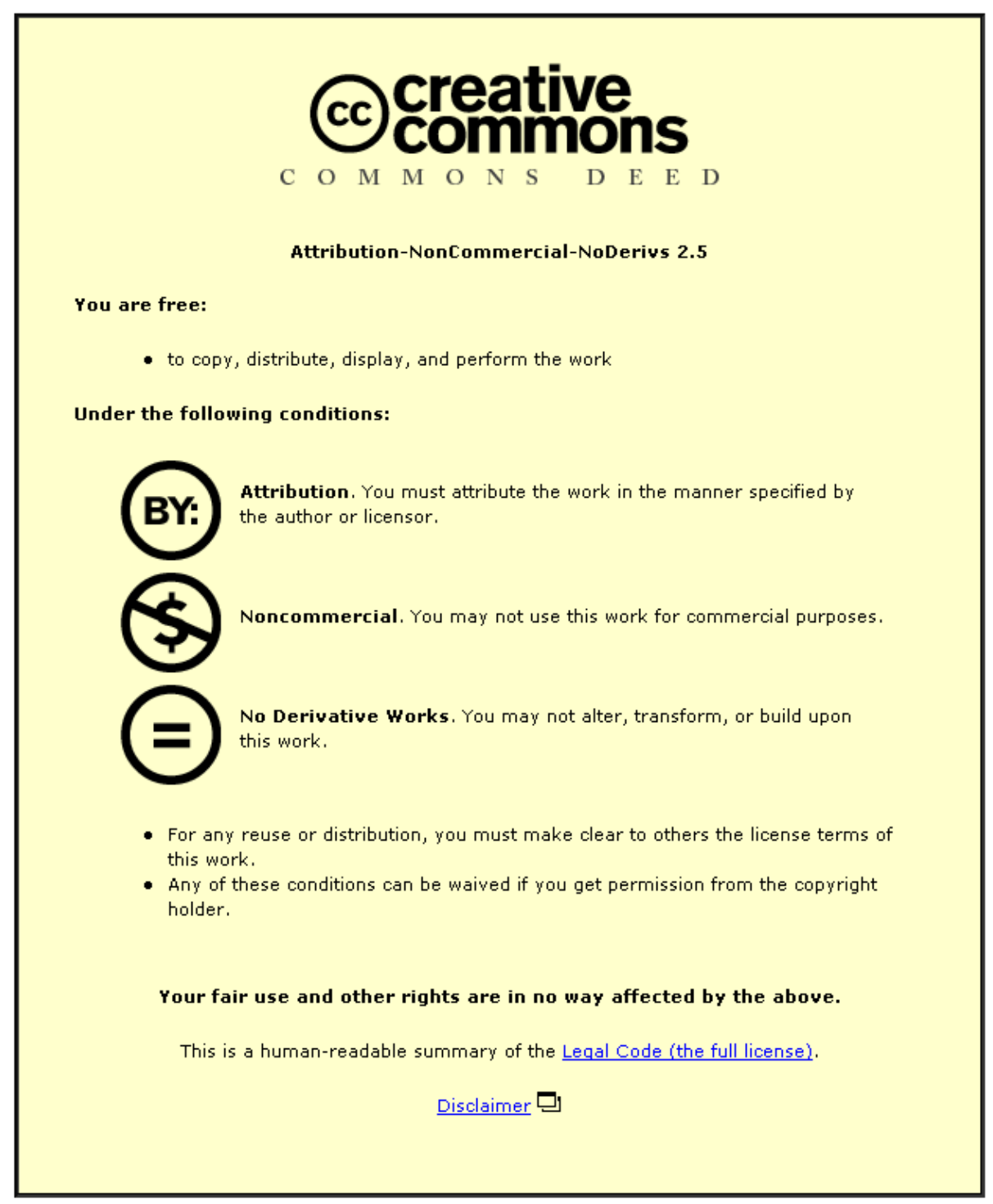

For the full text of this licence, please go to: http://creativecommons.org/licenses/by-nc-nd/2.5/ 


\section{Young People: A Phenomenographic Investigation into the Ways They Experience Information}

\section{Marian Smith and Mark Hepworth}

Dr. Marian Smith, Research Associate, Department of Information Science, Loughborough University, Loughborough, Leicestershire, Great Britain. Email: M.Smith7@lboro.ac.uk

Dr. Mark Hepworth, Reader, Department of Information Science, Loughborough University, Loughborough, Leicestershire, Great Britain.

E mail: M.Hepworth@lboro.ac.uk

This paper is based on a presentation at the international conference ' $i 3$ : Information: Interactions and Impact', organized by the Robert Gordon University's Department of Information Management, and held in Aberdeen, Scotland, 20-23 June 2011.

\section{Abstract}

This paper reports on a phenomenographic investigation into the ways young people, aged between eleven and eighteen years of age, experience information in both their academic and everyday life. Experience here is interpreted as the relationship between the subject (the young person) and the object (information). This research builds on previous studies of people's experience of information. However, other studies have had either a different focus, such as, focusing on information literacy, or, different respondents. Therefore this research addresses a gap in the knowledge. Three research questions are addressed in this paper: What are the qualitatively different ways young people experience information? What are the logical relationships between the categories of description? Can a holistic picture of young people's relationship with information be composed from knowledge of the different ways young people experience information? The study used a phenomenographic research approach to elicit and describe the qualitatively different ways in which young people experienced information. A purposeful sample of forty-one young people aged eleven to eighteen years participated in the study. The data, which were gathered through drawings and semi-structured interviews, were subjected to a rigorous process of phenomenographic analysis. The outcome of phenomenographic analysis is an outcome space consisting of a finite set of categories of description which, with their relationships, explain the different ways people experience phenomena in the world. In phenomenographic research, the focus is on the collective rather than the individual experience. The purpose of the study was therefore to highlight differences within the sample. In this study, six ways of experiencing information were identified: knowledge of sources of information; receiving information; process of finding information; store of unprocessed information; processing information; and use of information. The findings demonstrate some broad similarities with other studies. However, there are significant differences. The paper, therefore, gives a new insight into young people's experience of information. It also highlights the complex and multi-faceted way that young people experience information. These views help to understand what young people need to know and be able to do.

\section{Introduction}

This paper reports on a phenomenographic investigation into the ways young people, aged between eleven and eighteen years of age, experience information in both their academic and everyday life. The research seeks to investigate how young people experience information in all areas of their lives both academic and social. It is important to know and understand how young people relate to and experience information because:

... in order to make sense of how people handle problems, situations, the world, we have to understand the way in which they experience the problems, the situations, the world that they are handling or in relation to which they are acting. (Marton and Booth 1997, 111)

It is anticipated that an understanding of the ways in which young people experience information will have a relevance to a number of parties including educa- 
tors, and the library and information science (LIS) community.

In this study experience is interpreted as the relationship between the subject (the young person) and the object (information). According to phenomenographic principles experience is not a mental representation or a cognitive structure. 'Experience' is described as a relationship formed between the individual and the world (Marton 2000, 105). The term embodies the differing ways people experience, conceive, perceive and understand various phenomena in, and aspects of, the world around them (in this case information) (Marton 1986, 31).

Three research questions are addressed in this paper:

- What are the qualitatively different ways young people experience information?

- What are the logical relationships between the categories of description?

- Can a holistic picture of young people's relationship with information be composed from knowledge of the different ways young people experience information?

\section{Previous studies}

Young people's interactions with information have been investigated from a range of perspectives: information seeking (Chelton and Cool 2004, 2007; Large, Nesset, and Beheshti 2008; Head and Eisenberg 2009); use of the Internet (Livingstone and Bober 2005; Oblinger and Oblinger 2005; Large 2006; Livingstone 2006; Lenhart et al. 2007). The impact of the Internet on young people has been reported on by the Pew Internet and American Life Project (2012). In the UK Rowlands et al. (2008), in a report commissioned by the Joint Information Systems Committee (JISC) and the British Library identified how specialist researchers of the future (those born after 1993) were likely to interact with digital resources in the future. However the report differs from the present study in that it primarily reports on the information behaviour of young people across a large population. In the US a large-scale study, Project Information Literacy (PIL) at the University of Washington (http://projectinfolit.org/), is conducting similar research into students' information behaviour and research habits. The research reported here builds on this body of work but it differs significantly from the aforementioned studies because it focuses specifically on the variety of ways young people experience the phenomenon of information.

A number of previous studies have looked at people's experience of information. However, some studies have had a different focus such as: Information literacy (Bruce 1997; Boon, Johnston and Webber 2007); information seeking and use (Limberg 1999); information seeking (Edwards 2005); young people's information universes (Shenton 2002). Other studies have looked at different respondents, such as: Undergraduate women's experience of using information (Maybee 2007); firemen and information literacy (Lloyd 2006); teachers' conceptions of students' information literacy (Williams and Wavell 2007).

A review of the literature, therefore, revealed that there has been little published research to date focusing explicitly on young people's experience of information. Studies by Shenton (2002), Shenton and Johnson (2008) and Shenton, Nesset and Hayter (2008) have shown that there is a variance in the way young people understand the term information. However, there is no depth of research relating specifically to the ways in which young people experience the phenomenon of information. The intent of the research reported here was to fill the gap in the literature, enabling young people to voice their experience of information in all areas of their life.

\section{Methodology}

\section{Phenomenographic research approach}

Phenomenography was developed in Sweden at the University of Gothenburg in the 1970s by a team of researchers led by Ference Marton as a qualitative research methodology to study learning. Since then it has been developed and refined and applied to a wide range of phenomenon (Bruce and Gerber 1995).

Phenomenography is a qualitative research approach that is empirically based. The objective of phenomenographic research is to determine variation in the ways individuals experience a phenomenon (Marton and Booth 1997, 124). A fundamental assumption underlying phenomenographic research is that there are a finite number of qualitatively different ways of perceiving a phenomenon. It is important to note that variation is not that of one individual; it is a 
description of the collective variation of the population studied. Like other qualitative methods, phenomenography is descriptive, but it is unique in its focus on qualitative variation in understanding a phenomenon. The intention of the present study was to uncover variations in the qualitatively different ways young people experience information.

A basic tenet of phenomenography is that the nature of reality is defined as non-dualistic. This implies that the subject and object are inseparable (Marton 2000, 105). The relationship between the subject and object is central to phenomenographic research. It is within this relationship - the 'internal relation' that meaning is constituted, and it is the varying character of this internal relation that forms the object of phenomenographic research. Through identifying relations it becomes possible to depict phenomena.

In phenomenography to experience something is to be aware of something. " ... the totality of our experiences we call awareness" (Marton and Booth 1997, 122). A way of experiencing something is linked to how an individual's awareness is structured. There are different levels of awareness. Awareness is structured in a particular way that gives meaning to an individual's conception of an object. A phenomenographic research approach seeks to identify which aspect of the experience is perceived of as most significant and is focused on.

Phenomenography recognises that a person may well experience a phenomenon in more than one way. The focus is not on the individual but on the group and analysis seeks to identify the different ways in which a phenomenon is experienced by the group. Phenomenographic researchers undertake research from a second order perspective. Their aim is to interpret other people's experiences of a particular phenomenon; in doing so it becomes necessary for the researcher to "bracket" their own values and judgements (Ashworth and Lucas 2000).

The outcome of a phenomenographic study is a diagrammatic representation known as an outcome space which is made up of a related set of a limited number of categories of description that together expresses the variety of ways in which a particular phenomenon is experienced by a group of individuals in a given context. Marton and Booth $(1997,111)$ describe phenomenographic research thus:

The unit of phenomenographic research is a way of experiencing something .... and the object of the research is variation in ways of experiencing something.

Categories of description are not formulated prior to data collection or data analysis. They emerge from the researcher's interpretive analysis of the data and describe the variety of ways in which a group of people in a specific context experience a phenomenon. An individual category does not constitute the phenomenon itself; it represents a unique way of experiencing the phenomenon being investigated.

\section{Data collection}

Prior to the start of the study, a meeting was held with 10 Year Seven students (aged 11 to 12 years) and 8 Year Twelve and Thirteen students (aged 16 to 18 years) to familiarise the researcher with young people's world of information. This enabled later interview questions to be phrased in a meaningful way. The sample was drawn from two co-educational schools for eleven to eighteen year olds in Derbyshire in the United Kingdom: a state comprehensive school and an independent school. The selection of participants was purposive, i.e. a non- random sample where participants were sought out to ensure that variability which might influence the ways in which participants experienced information would be represented in the data. In order to achieve this each school was asked to identify a group of young people from a wide range of backgrounds. Forty-one young people aged eleven to eighteen years old participated in the study.

All participants completed drawings and were interviewed. A total of forty-one interviews were conducted. Twenty-three short interviews that lasted in the region of fifteen minutes were conducted primarily to explore the drawings, and eighteen interviews, each lasting between fifty minutes and one hour and ten minutes, to explore in depth the information experience.

Tamm and Granqvist $(1995,207)$ state, “... drawings are a well established medium for assessing thoughts and perceptions that may not be immediately accessible at the verbal level." For this reason drawing appeared to be a particularly appropriate tool to use in the present research study. At the start of each interview participants were asked to draw the first thing they thought of when they heard the word information. The intention was not to analyse the 
drawings separately rather it was to allow the participants to take the lead in the interview process by providing concrete examples of information to start the interviews. They were also given the opportunity to write words of explanation (Shenton 2002). All interviews then proceeded with a discussion about how information was experienced, stemming from the drawing which had been completed by the participant. This was important because, when conducting a phenomenographic interview, one of the aims is to avoid the preconceptions of the interviewer being used to prompt thoughts about the topic. The completion of drawings enabled young people to provide a starting point for the interviews.

The semi-structured interviews which used a small number of pre-planned open ended questions were conducted to explore the ways in which participants experienced information. Questions asked included: 'What does information mean to you?', 'What is not information?' 'When do you use the term information?', 'Can you give an example of information? 'What do you understand information to be about?' Probing questions were used to stimulate reflective thought.

Communicative validity was established between the researcher and the participants (Sandberg 2000, 14). Prior to the interviews and again at the start of the interviews participants were informed that the researcher was interested in how they experienced information and assured that there were no right or wrong answers. This was important in terms of developing a common understanding between the participants and the researcher about what was discussed in the interview. During the interviews communicative validity was established by generating data through dialogue (Sandberg 2000, 14). This allowed the researcher to check that participants' comments were being correctly interpreted. Data were collected via interviews which employed a small set of open ended questions to stimulate discussion. The use of open ended questions encouraged young people to identify and describe the ways they experienced information and limited the possibility of the interviews being biased according to the researcher's experiences of the phenomenon. To increase the validity of the data, the researcher repeated statements made by the participants to give them the opportunity to express their reflected thoughts and to ensure that the researcher had understood their answers and give them the opportunity to correct any misinterpretations. Probing questions were also used as a means to stimulate participants to elaborate and clarify their descriptions of the ways they experienced information.

\section{Data analysis}

All interviews were recorded and transcribed verbatim by the researcher and then subjected to an iterative process to identify fundamental categories of description in the data and a structural framework outlining the logical relationships between categories. The analysis aimed to group the participants' different experiences of information into categories of description according to the dimensions of variation.

Analysis followed the procedures outlined by Bruce (1997). In order to become familiar with the data all of the transcripts were read at least four times and each recording was listened to in its entirety at least twice. After that, the first phase of the phenomenographic analysis began. Sections of the transcripts relevant to the questions being asked were selected and marked. The selected parts of the data were then examined to identify themes and significant words, sentences and extracts were underlined and labelled with one or more key words reflecting the different ways participants experienced information.

After the initial themes had been identified, the selected parts of the data were taken from individual transcripts and pooled, shifting attention from the individual to the meanings expressed by the group as a whole. Hence it should be noted that analysis of the differences in the ways information was experienced by the different age groups within the sample was not the focus. In phenomenographic research the focus is on the collective rather than the individual experience. The purpose of the study was therefore to highlight differences within the sample.

Once the data had been pooled the analysis continued with the identification of distinct ways of perceiving information by comparing extracts and searching for similarities and differences. As the distinct ways of perceiving information were identified they were grouped on the basis of their similarities and differentiated from one another in terms of their differences. At all times the researcher was interpreting the participants' responses in relation to the phenomenon; seeking to identify which perceptions were held in focal awareness. 
Preliminary categories of description were then identified and illustrative quotes were included with the categories. A category of description represents one way of experiencing the phenomenon. Labels were constructed for the categories when the researcher was content that the data has been condensed to its core meaning. The label must capture the essence of the participants' perception of information.

The categories of description emerge from this iterative process and are not formulated prior to data collection and analysis. There is no attempt to fit the data into pre determined categories. Next came the constitution of an outcome space. This was done by determining the logical relationships between the categories of description.

Interpretative awareness “... to acknowledge and explicitly deal with our subjectivity throughout the research process instead of overlooking it" (Sandberg 1997,209 ) was used throughout the study to check and control the quality and consistency of the researcher's interpretation process. To maintain interpretive awareness Sandberg (1997, 209-210) suggests the following criteria are met:

- Suspension of researcher's theories and biases

- Accurate description of the individual's conception rather than providing explanation

- Equal importance paid to all aspects of an individual's experience

- Search for structure of meaning by focusing on the relationship between the 'what' and 'how' aspects of the experience

Throughout this research all of the aforementioned criteria were met ensuring that interpretive awareness was achieved.

Reliability as interpretive awareness means acknowledging researcher bias and explaining how it is dealt with in the study. This was implemented throughout the data collection and analysis through a process of bracketing prior knowledge and experiences of information. It was important at all times during the analysis process for the researcher to maintain an open-mind, avoiding any preconceived ideas of their own about the phenomenon in question. In phenomenographic research the participants' accounts are treated as objective data. The technique of bracketing was applied throughout the research process. Ashworth and Lucas $(2000,297)$ discuss in detail the need to bracket; they state that "steps must be taken - at the beginning and throughout the research - to bracket anything that would lead us from the student experience."

The researcher described accurately what constituted the phenomenon of information rather than explaining why it appears as it does. Interview questions directed the participants to focus on what the phenomenon meant for them. The use of quotes to provide evidence in support of the descriptions was another strategy used to ensure that analysis was faithful to the text.

Equal importance was paid to all aspects of individuals' experience in both the data collection and analysis stages of the phenomenographic research process. During the interviews each statement made by a participant was considered worthy of following up. In the data analysis stage of the research process no statement was dismissed all were considered equally.

The search for the basic structure of meaning was achieved by focusing on the relationship between the subject and object and repeatedly checking the variety of interpretations as the data were read until the meaning structure of the experience was stabilised (Sandberg 2005, 61).

\section{Critical reflection}

The intention of the present study was to uncover variations in the qualitatively different ways young people experienced information. Consideration was given to a number of research approaches including repertory grid technique and grounded theory however phenomenography as a methodology tries to capture the core ways in which a group experience a phenomenon and how the ways differ qualitatively as well as their relationships with each other. Accordingly a phenomenographic research approach was considered the most appropriate research approach to employ.

It is, however, acknowledged that there are limitations associated with this study. As outlined the research was conducted using a single research approach phenomenography which was considered the most appropriate to answer the research questions. It is, however, recognised that the use of a single research approach excludes understanding that might be provided by the use of other approaches.

Phenomenography uncovers the variety of qualitatively different ways a phenomenon is understood 
by a collective group of individuals in a given context. Therefore it cannot be employed to connect individual participants with specific experiences; neither can it be used to ascertain the prevalence of experiences within a population. There may have been distinctions between the different age groups in the sample, but it was outside the scope of the methodology, which looks at the collective voice of the group.

The study focused on two co-educational secondary schools in Derbyshire in the United Kingdom using an in depth research approach with a small sample. It is not claimed that the findings are generalisable. Nevertheless they do provide a basis for future studies.

\section{Findings}

\section{Categories of experience}

The outcome of phenomenographic analysis is an outcome space consisting of a finite set of categories of description which, with their relationships, explain the different ways individuals experience phenomena in the world. Prior to discussion of the outcome space the categories of description are outlined, each include the meaning structure, i.e. the essential parts of the subject-object relation, and the structure of awareness, i.e. the arrangement of the levels of young people's awareness. Young people's words have been used to illustrate the different ways they experienced information. Data analysis shows that young people experience information in six qualitatively different ways.

\section{Category One: Knowledge of sources of information - information is experienced as residing in information sources.}

I like to know what is happening in the news. You can pick it up online or on the TV or newspapers but over Sunday lunch my mum and dad discuss the news with my granny and granddad and that is where I pick up most of the news. (WMIS7)

\section{Meaning structure}

The relation between people and information was described in terms of knowledge of a range of sources of information and their characteristics, which creat- ed an information landscape and provided individuals with access to information either through receiving it or by finding it. The outcome of this experience of information was individuals have knowledge of a range of sources of information. Information was viewed objectively as something external to the individual.

\section{The structure of awareness}

The focal point of the structure of awareness revealed in this category is knowledge of sources of information. Acquiring information whether that is finding information or receiving information was in the next level of awareness. Thoughts about the information itself, about internalising it in the knowledge base lay on the periphery of their structure of awareness and there was no awareness of how information was going to be used. Significantly, this was in contrast to the findings by Bruce $(1997,122)$ and Webber, Boon and Johnston $(2005,10)$ who found that participants in their studies who had a conception of information literacy where the central focus was on information sources did have an awareness of information use.

This category was similar to the findings of Bruce's (1997) 'information sources conception'; Lloyd's (2006) 'knowing the information landscape'; Maybee's (2007) 'finding information in sources' and Shenton's (2002) 'sources-driven' strand. However, young people were liberal in their interpretation of sources, including mobile phones, Facebook, Google etc. as well as books and people; "you can pick it [news] up online or on the TV or newspapers." They also identified the "natural environment" as a source of information. Their experience incorporated appreciating what sources contained; how they were organised; the need to evaluate and determine relevance and showed a critical awareness that teachers felt significant (Williams and Wavell 2007).

Category Two: Receiving information - information is experienced as something that is received.

Obviously as a student you get told lots of information everyday of your life but I mean you get told things at home too and in the workplace or whenever you walk into a shop and you see posters with offers and prices on them. (SMCS13)

I think it is because at a young stage we are probably, as a human race more able to absorb information we are given better so that we can 
go on to use it ... because we are so young and our minds are so spongy. (SMIS12)

\section{Meaning structure}

The relation between people and information was de-scribed in terms where individuals viewed themselves as receptacles of information. Individuals received information, which was sorted and either rejected or retained to construct a knowledge base. Constructing a knowledge base was the outcome of this experience of information. Information in this category was viewed objectively as something external to the individual.

\section{The structure of awareness}

Receiving information was the distinctive character of this category. What happened to the information after it was received i.e. the construction of a knowledge base was a secondary concern. Knowledge of the sources where information was encountered was situated on the periphery of the structure of awareness. There was no awareness of the use of information.

This category of description has not been highlighted by previous studies that tend to emphasise the constructive nature of the information experience. The findings throw new light on the information behaviour of young people; receiving information plays a significant part in their lives. Young people subdivided this category into receiving information know ingly and encountering information.

Young people who experienced receiving information knowingly reported receiving information by "being told/given/shown information." They were alert to the possibility of receiving information within certain contexts and had knowledge of the sources of information within those contexts i.e. they had knowledge of the information landscape. They did not necessarily identify a need or want for specific information prior to receiving it but were alert to the need to gather information to construct a knowledge base; they had an awareness of the need to invest in information for the future. Young people recognised that in certain contexts they were in a position, physically, to receive information. This has resonance with the notion of "information grounds" (Fisher, Landry, and Naumer 2006).

The experience of encountering information was similar to Erdelez's (2005) notion of encountering. Here, in comparison, young people were not consci- ous of being in a position or context where they would receive information. Information encountered included that received when something "caught my eye"; and via "reflection."

\section{Category Three: Process of finding information -} information is experienced as something that is found.

Well I, my mum and my sister went to the library and we tried to find a cooking book we wanted to make these nice cakes but they didn't have a book so we went to my nanas and had a look at her books and we found one. (ZMCS7)

\section{The meaning structure}

The relation between people and information can be described in terms of individuals engaging in a process to find information in order to fill a knowledge gap. The information which may be wanted and/or needed was found in sources of information held within their personal information landscape. The outcome of this experience of information was possession of a knowledge base that enables the knowledge gap to be filled and satisfied curiosity and/or resolved an information need. Information in this category was viewed objectively as something external to the individual.

\section{The structure of awareness}

The focal element of this category centred on the process of finding information. Individuals recognised a gap in their knowledge and engaged in a process to find information to fill that gap. The information was found in sources of information held within their personal information landscape, however knowledge of sources of information was not of prime concern and therefore it formed the second level of awareness. Knowledge base construction was found on the outer edge of the structure of awareness. There was no awareness of the use of information.

A number of authors have identified the 'process' experience, Bruce's (1997) 'executing a process'; Maybee's (2007) 'initiating a process' and Boon, Johnston and Webber's (2007) 'basic research skills'. Although, the latter implies a relatively systematic process incorporating 'library skills' whereas young people stated that it was not necessarily planned. Nevertheless participants did usually describe the search process as a set of steps comprising an infor- 
mation problem in the form of a need or want; action taken to satisfy the information need or want and a resolution of the information problem. The participants in Bruce's study $(1997,130)$ who experienced information literacy in terms of information processes, also described the process in a number of different ways but with the same core set of steps. Similarly to Dervin's (1983) conception of information seeking, it was associated with filling a gap. For example, "I had to look it up" or "using a bus timetable" to know what time to travel, were given as examples. Different strategies were used depending on the context. This process was often reported to be unsupported in the school environment with more emphasis on the product than the process itself.

\section{Category Four: Store of unprocessed information - information is experienced as something that is internalised, stored, but unprocessed.}

Yeah if it is simple information you don't think about it you just take it in then it just stays there instead of being processed. (SMCS13)

\section{The meaning structure}

Individuals who experienced information as it is described in this category viewed information as being stored within themselves. Information had been acquired from a range of sources and internalised. After a process of deciding whether information should be retained, it was stored without further processing, for potential future use or connection with new information. The outcome of this experience of information was that individuals stored information in a repository, which was housed in the knowledge base, for possible future use or to connect with new information.

\section{Structure of awareness}

Storing unprocessed information was the distinctive feature of this category. The term 'unprocessed' meant that the information was not subjected to any further thought, consideration or analysis. It was remembered as it was and stored. Information that was experienced in this way had the potential for use in the future therefore use of information formed the second level of awareness. Participants recognised that unprocessed information that was stored in a repository was, in its own right, part of a knowledge base. It was known information with the potential for future use. There was also some awareness that it might at some point in the future, link up with new information but this lay on the periphery of the structure of awareness. Acquiring information and knowledge of sources of information were referred to and comprised part of the meaning structure but with insufficient emphasis on either for them to make up part of the structure of awareness. The experience of information as it is described in Category Four (Store of unprocessed information) of this study is one that has not been referred to in previous studies.

Young people described information as it was experienced in Category Four as knowledge. The only criterion necessary for it to be knowledge was for it to be information that was known. The main criterion for information to be part of a knowledge base was not that it was processed but that the information was known; it was "knowledge." The fact that it was processed or unprocessed did not make a difference.

There was a divergence of opinion on whether or not information needed to be understood to be taken in and stored. Not all information was perceived as needing to be understood, for example, factual information that needed to be "regurgitated for exams." Participants experienced information, as described in this category, in a variety of contexts but it was notable that it was often perceived in this way in the school context.

Category Four shared some aspects of Bruce's (1997) conception 'information control' and the sense of managing information. In her study Bruce $(1997,132)$ referred to storing information in the Information Control Conception where the emphasis was on the human brain storing and controlling information. Bruce's Information Control Conception, however, was significantly different from Category Four, as described in this study, in that information was viewed as external to the individual and not integrated into the internalised knowledge base.

In Category Four participants were describing a type of information that did not require a great deal of engagement on their part. They experienced it as simple, factual information that was remembered. It did not necessarily need to be understood. It just needed to be remembered. It became part of their knowledge base and could be recalled from there in a state ready for future use.

Referring to this experience of information a number of participants made the point that information as printed in a textbook, which the teacher had directed them towards, was the "right information." It was 
exactly what the teacher wanted and any attempt by them to alter it in any way would be wrong. Lupton $(2008,402)$ in her analysis of the qualitative variation in students' experiences of information literacy lists 'finding the right answer' as one conception. This conception is associated with a surface approach to learning. The findings reported in this category highlight the fact that a number of young people understood that they were being asked by their teachers to find "the right information." This implies that they were reluctant to think about information, evaluate or alter it in any way. They were satisfied in the knowledge that if a teacher had directed them to information then the teacher had evaluated it and it did not need any further evaluation. In a sense, this stripped the young people of the need to evaluate information personally, described as a more advanced skill in Bloom's taxonomy of thinking (Bloom 1956).

Category Five: Processing information information is experienced as something that is internalised and processed.

Information is anything that is description, detail, fact or opinion that has to be processed by someone. It needs conscious thought. (SMIS12)

\section{The meaning structure}

In this category information was processed. Once acquired information was deemed fit for retention it was thought about, considered and analysed. Once analysed it could directly form part of the knowledge base however prior to this it might also connect with information already internalised i.e. information stored in the repository of information as described in Category Four or information previously processed and internalised in the knowledge base as described in Category Five. It was then held in the knowledge base and retained for possible future use. The outcome of this experience of information was processed to construct a knowledge base.

\section{Structure of awareness}

The focal element of this category was the processing of information. The internalised and sorted information was processed and could be linked with information already internalised. Individuals were aware that this processed information that had been retained formed part of a base of knowledge that had the potential to be put to future use; therefore information use formed the next level of awareness. Acquiring information (either receiving or finding information) was referred to by participants but was not a major element of this way of experiencing information and for that reason rests on the periphery of the structure of awareness.

In Category Five, information was thought about and analysed. Although they used the word "process" readily many young people when asked to expand on what they meant by the term were hesitant in replying. They were aware that they processed information but did not appear to have very much experience of relating how this was done. Some form of cognitive activity was applied to the information. Young people used terms like "pick out key points," "interpret" and "own version." This hesitation in explaining how information was processed was often apparent in the academic context but interestingly in the social context participants reported that information such as gossip was not always easily trusted and therefore they recognised the need think critically about it and to evaluate it.

Participants described information as something that they needed to engage with at a deeper level, that they needed to think about; to consider; to weigh up and to interpret. Processing information led to understanding. This way of experiencing information echoes Marton and Säljö's (1976a, 1976b) description of a deep learning.

This experience of information has similarities with Limberg's (1999) 'scrutinising and evaluating'; Maybee's (2007) 'building a personal knowledge base' and Bruce's (1997) 'knowledge construction' and 'knowledge extension', where 'novel insights' develop. It also corresponds to findings from a study of teachers' conceptions of student information literacy by Williams and Wavell (2007). They reported one of the conceptions as 'Making Meaning' conception. In this conception teachers conceived student information literacy as encompassing cognitive processes that helped students to make sense of information. Akin to the use of the word "learn" by participants in this study Shenton $(2002,176)$ noted that the young people of high school age in his study talked about information in terms of the effect it had on one's state of knowledge and they used the word learning. Shenton also found an association between information and mental processes including knowing, thinking, learning, concentrating and using your brain amongst young people of all ages. In the study by Webber, 
Boon and Johnston $(2005,11)$ one of the conceptions of information literacy held by marketing academics was 'Becoming critical thinkers'. This conception had similarities with Category Five in this study with a focus on becoming a critical thinker and an awareness of skills such as understanding and interpreting information.

Category Six: Use of information - information is experienced as something that is 'put into action'; it is used.

I'm going back to playing an instrument you use information to do that and you use it to get your marching right. You have information on how to do things and you put it into action when you need it. (KFCS13)

\section{The meaning structure}

In this category information was used. Young people had acquired and internalised information which now made up their knowledge base. Young people who experienced information in this way were aware of putting information to use that had been acquired and internalised, for a range of purposes. It might be applied to problems that needed resolving or tasks that needed addressing or it could be passed on and shared with others for a range of purposes. The outcome of this experience of information was information was used for a variety of reasons.

\section{The structure of awareness}

Using information was the distinctive feature of this category. Information which had been internalised was "put into action"; it was used. Information that was used had either been stored, unprocessed in the young person's repository of information within their knowledge base or it had been processed and constituted part of their knowledge base, therefore the knowledge base of internalised information formed the next level of awareness. In this category acquiring information appeared on the periphery of the structure of awareness because, although references were made about receiving and finding information, they were not prominent. As information was used young people recognised where that information came from. In the first instance it came from their personal base of knowledge and prior to that it was acquired from a source.

In this category information was accessed from the knowledge base at a point in time when it was needed.
Young people focused their attention on how information was used, how it was applied. This echoes the findings of Shenton $(2002,173)$ who noted that one of the strands identified in young people's definitions of information was the 'use related strand' where information was defined on the basis of its utility either actual or perceived. In this study, young people indicated that, they had to consider how the information should be used and whether, for example, to "act on gossip." This is, perhaps, analogous to Bruce's (1997) seventh conception 'wisdom.'

\section{The outcome space}

The outcome space is described by Marton (1986, 34) as a structural framework housing the categories of description and by Bruce $(1997,87)$ as a diagrammatic representation of the logical relationships between the different conceptions of a phenomenon. In order to reveal the structural relationships between all of the categories the outcome space in this study is presented as three diagrammatical representations illustrated in Table 1, Figure 1 and Figure 2.

Table 1 illustrates the dimensions of variation in how information is experienced in relation to the individual and how information is operated on. It also indicates the hierarchical nature of the relationship between the categories of experience.

\section{Outcome space derived from the meaning}

structures and structures of awareness

Figure 1 demonstrates the dimensions of variation and relationships between the meaning structures of the different categories. Consideration is given to how the essential parts of the meaning structures demonstrate the variations between each of the ways in which information is experienced. The essential parts are presented in emboldened text. Looking at the essential parts of the meaning it can be seen that there are inclusive hierarchical relationships between the categories where categories further up the hierarchy include the previous or lower ones. Arrows indicate the inclusive hierarchical nature of the outcome space.

Figure 2 demonstrates the dimensions of variation and relationships between the structures of awareness for each category. Each awareness structure is made up of three components: the focal point, the second level of awareness and the peripheral level of aware- 
Table 1. The dimensions of variation in how information is experienced in relation to the individual and how information is operated on.

\begin{tabular}{lcc}
\hline Category & $\begin{array}{c}\text { How information is experienced in relation } \\
\text { to the individual }\end{array}$ & How information is operated on \\
\hline One: knowledge of sources & External & Observed \\
Two: receiving information & External & Received \\
Three: finding information & External & Found \\
Four: store of unprocessed information & Internal & Stored \\
Five: processing information & Internal & Processed \\
Six: information use & Internal & Used \\
\hline
\end{tabular}

ness. Together these components constitute the way information is experienced in each category by individuals in the study.

\section{Hierarchy}

The categories of description and their relationships are outlined in an inclusive, hierarchical, outcome space. The outcome space is hierarchical in the sense that the ways of experiencing information identified range from simple to more sophisticated. Categories are placed on levels and the levels are hierarchical. Levels placed higher up the hierarchy embrace levels lower down the hierarchy. Four levels of complexity are indicated. At the least complex level young people's focus was on knowledge of information sources (Category One). Information was experienced as something external to the individual which was also the case in Categories Two and Three. In Categories Four, Five and Six information was experienced as something internalised by the individual. The categories are arranged in ascending order of complexity.

- Level One: Information landscape (Category One: Knowledge of sources of information);

- Level Two: Acquisition of information (Category Two: Receiving information; Category Three: Process of finding information);

- Level Three: Knowledge base of internalised information (Category Four: Store of unprocessed information; Category Five: Processing information);

- Level Four: Application of information (Category Six: Use of information).

The levels of hierarchy and description of complexity are outlined below:
Level One: Information landscape (Category One:

Knowledge of sources of information);

Category One has been placed on Level One because it is the least complex way of experiencing information. In this category information was seen as an external entity. There was no focus on interacting with information. Information existed within the source but knowing the information landscape i.e. knowledge of the source of information and its characteristics was paramount. Compared to all the other categories, young people who experienced information as described in Category One had the least complex relationship with information.

\section{LevelTwo: Acquisition of information (Category Two: Receiving information, Category Three: Process of finding information);}

Category Two (Receiving information) and Category Three (Process of finding information) have been placed on Level Two. Although information was still understood as something external, the experience of information was more complex than in the case of Category One because in these two categories there was interaction with information. Young people who experienced information as described in Categories Two and Three had awareness of the information landscape and building a knowledge base.

\section{LevelThree: Knowledge base of internalised information (Category Four: Store of unprocessed information, Category Five: Processing information); Category Four (Store of unprocessed information) and Category Five (Processing information) have been placed on Level Three because in both categories the experience of information was more complex than in}


Figure 1. Outcome space showing the relationships between the categories derived from meaning structures.

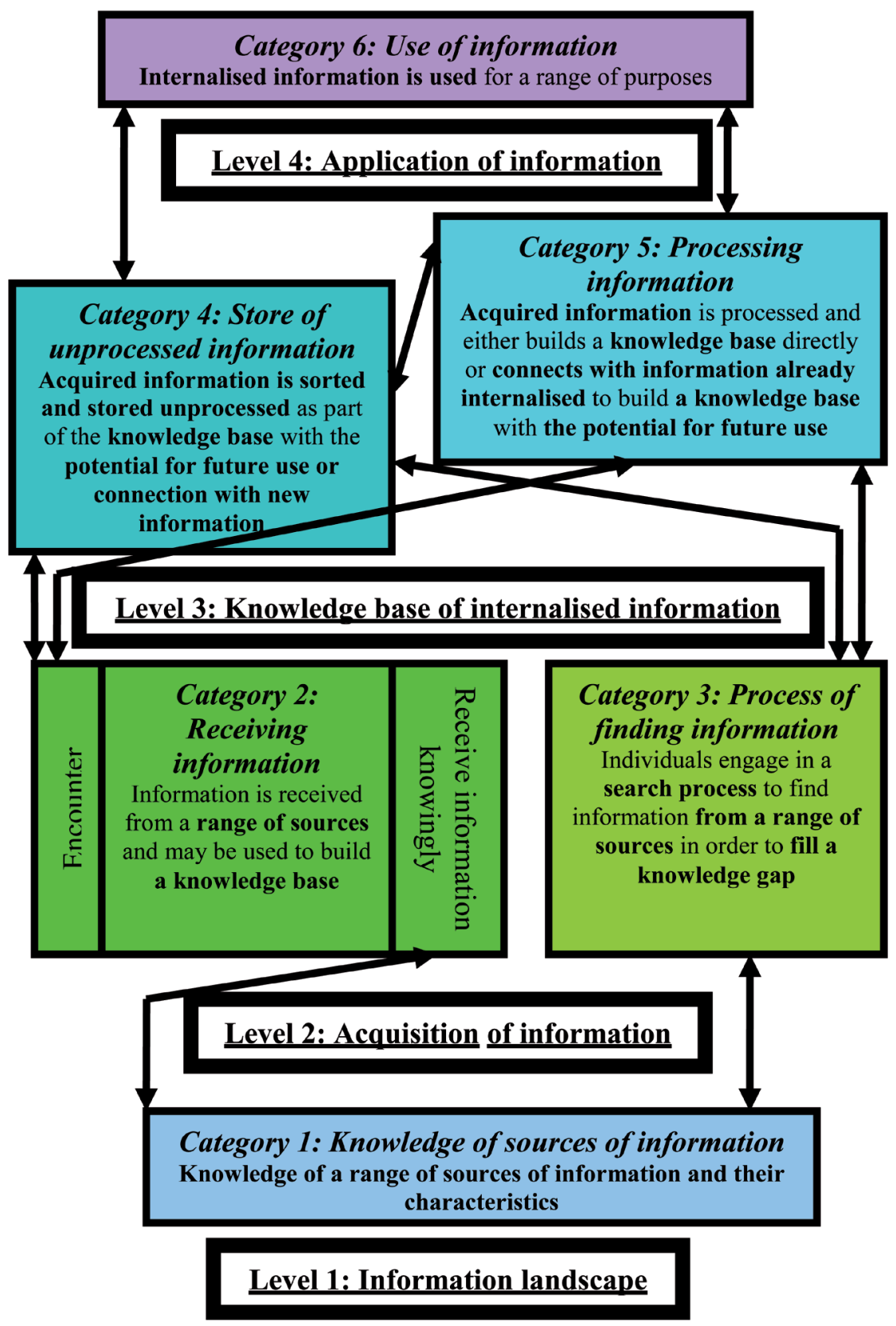

Arrow indicates the inclusive hierarchical

nature of the outcome space. 
Figure 2. Outcome space showing the relationships between the categories derived from structures of awareness.
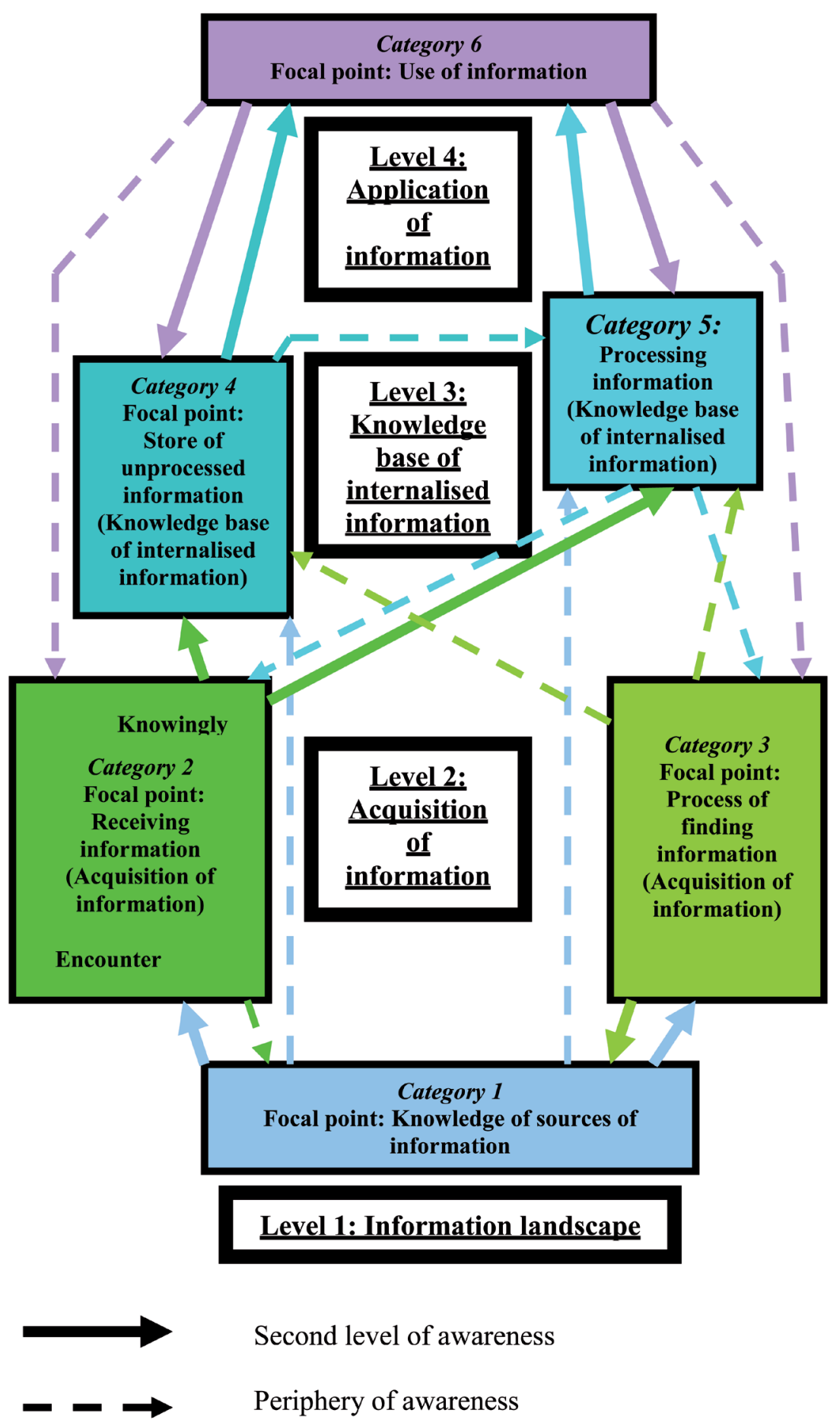
the previous three categories. Information was internalised and formed a knowledge base. There was a hierarchy within this level. The experience of information in Category Five was more complex than in Category Four and therefore Category Five is placed higher up the hierarchical structure.

\section{Level Four: Application of information (Category Six: Use of information).}

Category Six (Use of information) is at the top of the hierarchy on Level Four. In this category the experience of information was more complex than in Categories Four and Five. In Category Six information which had been internalised and formed a knowledge base was used.

\section{Discussion}

Given the environment that young people live in today, where sources of information are much in evidence both in the home and in the academic environment, it is not surprising that one of the ways they experience information is in terms of their relationship with sources of information (Category One). Information can be seen as an abstract phenomenon and some young people, and possibly people in general, may find it easier to refer to a concrete representa-tion of information in the form of an information source. This is highlighted to an extent in Category Three where the process of finding information is the central focus of awareness and at the second level of awareness lies knowledge of sources of information. In Category Three young people showed no awareness of what use the information was going to be put to. Even at the peripheral level of their structure of awareness there was no awareness of information use. This differs significantly from the awareness structure Bruce (1997) found amongst higher educators in her study where the second level of awareness described in the 'information process' conception was not on sources of information but on information use.

One possible explanation for this difference could be that, compared to the higher educators in Bruce's study (1997), the young people in the present study had not received enough training or practice in thinking about how information could be used in relation to dealing with a situation. This is significant because, as Moore (2000) notes in her study of primary school children in New Zealand, having an understanding of how information is going to be used enables students to evaluate information. An awareness of information use could also facilitate the decision on how to internalise information appropriately into the knowledge base, whether or not it should be processed. Reflection and thinking about how information may be used before it is internalised in the knowledge base could facilitate the cognitive storage and management of information and may help with information retrieval at the point of use.

In the structure of awareness for Category Six the second level of awareness is knowledge base of internalised information and on the periphery level of awareness is acquisition of information. This structure of awareness suggests that when young people use information for whatever purpose they go through a period of reflection which involves them in a procedure where they conduct a search. They search their knowledge base for the information they need and then they evaluate that information on the basis of where the information was acquired from. This procedure implies the need for individuals to be aware of the importance of managing the storage of information in their knowledge base in an efficient manner, for example, associating information with other information. In order to help achieve this it is important for individuals to think about how information is to be used before it is internalised.

The ways that information is experienced in categories Four and Five give an insight into how young people engage with learning. As exemplified in Category Four some young people fail to engage with, and in some cases, even understand the information they are storing. This behaviour is reinforced by their notion of looking for the "right" information to which the teacher had directed them. This implies that learning is taking place at a surface level and not at a deep level, hence, placing little emphasis on critical thinking and analytical skills. It is worth noting that participants who experienced information as described in Category Five regularly referred to acquiring the information as a result of being intrinsically motivated to do so through interest or curiosity. This finding resonates with that of Heinstrom (2006) who found that students who were intrinsically motivated did not merely want to complete a task but wanted to learn. Heinstrom (2006)) found that extrinsically motivated students regarded information seeking mainly as gathering enough facts to complete a task. It is possible to speculate that young people who experience 
information, primarily, as described in Category Four may be less motivated and less engaged than young people who experience information as described in Category Five.

The six categories indicate that young people do have a sophisticated relationship with information. For example, recognising that the natural environment is a source of information and that placing oneself in a specific context could be informative. Plus the role of chance encounters of information.

\section{Conclusion}

This study corroborates and also builds on previous research. The study has highlighted the complex and multi-faceted way that young people experience information. The purpose of the study was to uncover the variations in the different ways young people experience information. The six distinct categories of experience which were identified address the first research question by describing the qualitatively different ways young people experience information. The second research question is addressed in the outcome space where the logical relationships between the categories of description are outlined. A combination of these provides a holistic picture of young people's relationship with information, satisfying the third research question.

As outlined in the findings and discussion sections, this research has demonstrated that there are broad similarities with previous studies but also, importantly, significant differences. New light has been thrown on the information behaviour of young people. Receiving information plays a large part in their lives. This category of description has not been highlighted by previous studies that tend to emphasise the constructive nature of the information experience.

In Category Four, participants experience information as unprocessed and stored in the knowledge base. Although there are some commonalities with findings from Bruce's study (1997) the experience of information as it is described in Category Four of this study is one that has not been referred to in previous studies. In Category Four, participants reported experiencing information to mean factual knowledge which needs to be stored and regurgitated when necessary. It does not necessarily need to be understood. This is particularly evident in the academic environment. This implies that they experience a lack of emphasis on critical, analytical thinking and a greater emphasis on delivering the 'right' information. Furthermore, in school, reward tends to be heavily weighted on the final product i.e. the report, rather than the 'journey' of finding out. Hence, the learner places less value on, and develops less expertise in, the research process (Smith and Hepworth 2007, 10). In fact, it is often a task that takes place out of school without support.

Of significance and in contrast to previous studies (Bruce 1997; Webber, Boon, and Johnston 2005) there was no awareness of information use in the first three categories of description. This could be expected to have implications with regard to appropriately managing the internalisation of information and also the evaluation of information. It was evident that consciousness of how information was to be used was a more complex way of experiencing information and less evident among some young people. This indicates a need to help young people to be more conscious about the nature of the information that they need to answer a question i.e. how they will use the information; since this is likely to enable them to undertake more effectively the identification of sources, the finding, evaluating and processing of information. This in turn was linked to motivation and implies that pedagogy, that encourages information literacy, needs to foster motivation and engagement with the process, for example, by allowing learners to have a greater role in defining and choosing the topic that is investigated.

This research has potential practical implications. Understanding young people's experience of information and realising the complexity of their experience provides teachers of information literacy with a foundation that can be built upon. The findings from this research can be used to structure the delivery of information literacy training. This has already taken place at Loughborough University. Module ISA309 Studying Information Science is delivered to first year undergraduate students. It aims to give them an understanding of information science and prepare them for successful study at university. This module has now been structured drawing on the knowledge gained from the study and appears to have been successful in enabling engagement. For instance students were asked to reflect on how they perceived the information environment and how they processed information. One specific example of encouraging the critical evaluation of information was to ask the students to reflect on how they dealt with gossip i.e. 
how they evaluated it and then in the light of this to consider how they would evaluate academic information. Such an approach could also be developed for delivery to students in secondary education. Furthermore the findings suggest that the process of interacting with information needs to be supported and rewarded. They also suggest the need for a greater emphasis on the use of information and more independent learning i.e. more exploratory work, topics of more relevance and more definition of the task. Understanding young people's experience of information and realising the complexity of their experience also helps us to see learners in a positive light rather than from a negative standpoint that is often implied by the term "the Google generation".

The framework of categories of experience, and appreciating their hierarchical nature, provides a structure that could be used by teachers of information literacy. Using these categories, that reflect the learners experience, could better enable young people to engage with information literacy. However, further research would be required to determine whether or not this is the case. The categories of experience also deserve further exploration, involving young people in further studies, and teasing out the cognitive, emotional and behavioural elements associated with their information behaviour and how these vary with different tasks and media.

\section{References}

Ashworth, P., and U. Lucas. 2000. "Achieving Empathy and Engagement: A Practical Approach to the Design, Conduct and Reporting of Phenomenographic Research." Studies in Higher Education 25 (3): 295-308.

Bloom B. S. 1956. Taxonomy of Educational Objectives, Handbook I: The Cognitive Domain. New York: David McKay Co. Inc.

Boon, S., B. Johnston and S. Webber. 2007. "A Phenomenographical Study of English Faculty's Conceptions of Information Literacy." Journal of Documentation 63 (2): 204-228.

Bruce, C. 1997. The Seven Faces of Information Literacy. Adelaide, South Australia: Auslib Press.

Bruce, C., and R. Gerber. 1995. Phenomenographic Research: An Annotated Bibliography. 3rd ed. Accessed August 15, 2010. http://sky.fit.qut.edu.au/ bruce/anabib/title.php.

Chelton, M. K., and C. Cool, eds. 2004. Youth Information Seeking Behavior: Theories, Models and Issues. Lanham, MD: Scarecrow Press.

Chelton, M. K., and C. Cool, eds. 2007. Youth Information Seeking Behavior II: Context, Theories, Models, and Issues. Lanham, MD: Scarecrow Press.
Dervin, B. 1983. "Information as a User Construct: The Relevance of Perceived Information Needs to Synthesis and Interpretation." In Knowledge Structure and Use: Implications for Synthesis and Interpretation, edited by S. A. Ward and L. J. Reed, 153-184. Philadelphia, PA: Temple University Press.

Edwards, S. L. 2005. "Panning for Gold: Influencing the Experience of Web Based Information Searching." PhD thesis, Queensland University of Technology.

Erdelez, S. 2005. "Information Encountering." In Theories of Information Behaviour, edited by K. Fisher, S. Erdelez and L. McKechnie, 179-184. Medford, NJ: Information Today Inc.

Fisher, K. E., C. F. Landry, and C. Naumer. 2006. "Social Spaces, Casual Interactions, Meaningful Exchanges: 'Information Ground' Characteristics Based on the College Student Experience." Information Research 12 (2): paper 291. Accessed August 28, 2011. http://informationr.net/ir/12-2/paper291.html.

Head, A. J., and M. B. Eisenberg. 2009. Lessons Learned: How College Students Seek Information in the Digital Age: Project Information Literacy Progress Report. Seattle, WA: University of Washington, The Information School. Accessed January 16, 2012. http://projectinfolit.org/pdfs/PIL_Fall2009_finalv_ YR1_12_2009v2.pdf.

Heinstrom, J. 2006. "Fast Surfing for Availability or Deep Diving into Quality - Motivation and Information Seeking among Middle and High School Students." Information Research 11 (4): paper 265. Accessed March 29, 2011. http://InformationR. net/ir/11-4/paper265.html.

Large, A. 2006. "Children, Teenagers and the Web." In Annual Review of Information Science and Technology 39, edited by B. Cronin, 347-392. Medford, NJ: Information Today Inc.

Large, A., V. Nesset, and J. Beheshti. 2008. "Children as Information Seekers: What Researchers Tell Us." The New Review of Children's Literature and Librarianship 14 (2): 121-140.

Lenhart, A., M. Madden, A. R. Macgill, and A. Smith. 2007. Teens and Social Media. Pew Internet and American Life Project, December 19. Accessed January 22, 2012. http://www. pewinternet.org/ /media//Files/Reports/2007/PIP_Teens_ Social_Media_Final.pdf.pdf.

Limberg, L. 1999. "Three Conceptions of Information Seeking and Use." In Exploring the Contexts of Information Behaviour: Proceedings of the Second International Conference on Research in Information Needs, Seeking and Use in Different Context, 13-15 August 1998, Sheffield, edited by T. Wilson, and D. Allen, 116-135. London: Taylor Graham.

Livingstone, S. 2006. "UK Children Go Online: End of Award Report”. Accessed January 16, 2012. http://www.lse.ac.uk/ collections/children-go-online/End $\% 20$ of $\% 20$ Award $\% 20$ Report, \%20UK\%20Children\%20Go\%20Online,\%20 Sonia\%20Livingston.pdf .

Livingstone, S., and M. Bober. 2005. "UK Children Go Online: Final Report of Key Project Findings.” Accessed January 16, 2012. http://www.lse.ac.uk/collections/children-go-online/ UKCGO_Final_report.pdf.

Lloyd, A. 2006. "Information Literacy Landscapes: An Emerging Picture." Journal of Documentation 62 (5): 570-583.

Lupton, M. 2008. "Evidence, Argument and Social Responsibility: First Year Students' Experiences of Information Literacy when Researching an Essay." Higher Education Research and Development 27 (4): 339-414. 
Marton, F. 1986. "Phenomenography: A Research Approach to Investigate Different Understandings of Reality." Journal of Thought 21 (30): 28-49.

Marton, F. 2000. "The Structure of Awareness." In Phenomenography, edited by J. Bowden and E.Walsh, 102-116. Melbourne: RMIT Publishing.

Marton, F., and S. Booth. 1997. Learning and Awareness. Hillsdale, NJ: Lawrence Erlbaum Associates.

Marton, F., and R. Säljö. 1976a. "On the Qualitative Difference in Learning I- Outcome and Process." British Journal of Educational Psychology 46: 4-11.

Marton, F., and R. Säljö. 1976b. "On the Qualitative Difference in Learning II-Outcome as a Function of the Learner's Conception of the Task." British Journal of Educational Psychology 46: 115-127.

Maybee, C. 2007. "Understanding our Student Learners: A Phenomenographic Study Revealing the Ways that Undergraduate Women at Mills College Understand Using Information." Reference Services Review 35 (3): 452-462.

Moore, P., 2000. "Primary School Children's Interaction with Library Media: Information Literacy in Practice." Teacher Librarian 27 (3). Accessed January 21, 2012. http://www. davidvl.org/250coursespr04/b66.pdf

Oblinger, D., and J. Oblinger, eds. 2005. Educating the Net Generation. Washington, DC: Educause. Accessed January 14, 2012. http://www.educause.edu/ir/library/pdf/pub7101.pdf.

Pew Internet. 2012. "Pew Internet and American Life Project." Accessed January 16, 2012. http://www.pewinternet.org.

Rowlands, I., D. Nicholas, P.Williams, P. Huntington, M. Fieldhouse, B. Gunter, R. Withey, H.R. Jamali, T. Dobrowolski, and C. Tenopir. 2008. "The Google Generation: The Information Behaviour of the Researcher of the Future." Aslib Proceedings 60 (4): 290-310.

Sandberg, J. 1997. "Are Phenomenographic Results Reliable?" Higher Education Research and Development 16 (2): 203212.
Sandberg, J. 2000. "Understanding Human Competence at Work: An Interpretative Approach.” Academy of Management Journal 43 (1): 9-25.

Sandberg, J. 2005. "How do we Justify Knowledge Produced within Interpretive Approaches?" Organizational Research Method 8 (1): 41-68.

Shenton, A. K. 2002. "The Characteristics and Development of Young People's Information Universes." PhD thesis, Northumbria University.

Shenton, A. K., and A. Johnson. 2008. "Young People's Perspectives on 'Information' Revisited." IFLA Journal 34 (3): 238255.

Shenton, A. K., V. Nesset, and S. Hayter. 2008. "Children's Conceptualizations of the Word 'Information'." Journal of $\mathrm{Li}$ brarianship and Information Science 40 (3): 151-164.

Smith, M., and M. Hepworth. 2007. "An Investigation of Factors that may Demotivate Secondary School Students Undertaking Project Work: Implications for Learning Information Literacy." Journal of Librarianship and Information Science 39 (1): 3-15.

Tamm, M. E. and A. Granqvist. 1995. "The Meaning of Death for Children and Adolescents: A Phenomenographic Study of Drawings." Death Studies 19 (3): 203-222.

Webber, S., S. Boon, and B. Johnston. 2005. "A Comparison of UK Academics' Conceptions of Information Literacy in Two Disciplines: English and Marketing." Library and Information Research 29 (93): 4-15.

Williams, D., and C. Wavell. 2007. "Secondary School Teachers' Conceptions of Student Information Literacy." Journal of $\mathrm{Li}$ brarianship and Information Science 39 (4): 199-212.

Editorial history:

Paper received 26 October 2011

Revised version received 24 April 2012

Accepted 27 April 2012 